\title{
Estado nutricional e práticas alimentares de trabalhadores acidentados ${ }^{1}$
}

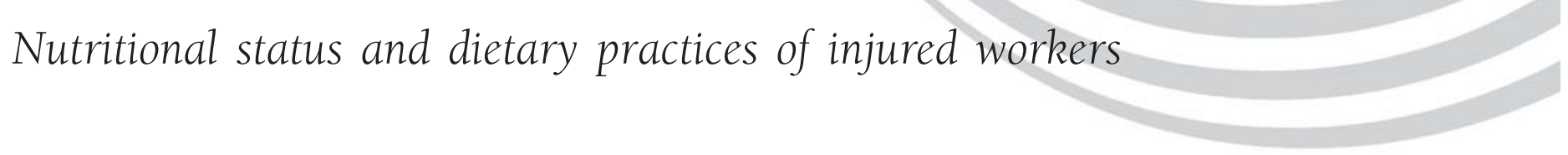

Maria Angélica Tavares de MEDEIROS²

Ricardo CORDEIRO3

Lia Thieme Oikawa ZANGIROLANI ${ }^{3}$

Rosa Wanda Diez GARCIA ${ }^{4}$

\section{RE S U M O}

\section{Objetivo}

Identificar o estado nutricional e as práticas alimentares de trabalhadores acidentados de Piracicaba, SP.

\section{Métodos}

Estudo transversal com 600 trabalhadores acidentados, atendidos em um dos 8 serviços especializados do município, entre maio e outubro de 2004. Foram caracterizados a situação socioeconômica, ocupacional, as práticas alimentares e o estado nutricional (peso, altura e circunferência de cintura), verificando médias e desvio-padrão.

\section{Resultados}

Os acidentados eram, fundamentalmente, homens $(87,33 \%)$, operários $(55,17 \%)$, com idade média de 33 anos. A maioria se inseria no mercado formal $(84,17 \%)$, em turno diurno fixo $(91,00 \%)$, e $55,33 \%$ possuía trabalho fixo. Aproximadamente a metade deles apresentou sobrepeso (28,26\%) ou obesidade (17,89\%), sendo maior nos que referiam pouco esforço físico no trabalho (54,90\%). Quase 1/3 dos trabalhadores tinha a circunferência da cintura aumentada, indicando risco cardiovascular. O benefício alimentação atendia a $85,33 \%$ dos entrevistados. Predominou, na rotina alimentar, a realização de duas grandes refeições, almoço $(95,67 \%)$ e jantar (94,83\%); $24,16 \%$ não ingeriam o desjejum diariamente, e $37,50 \%$ consumiam alimentos entre as grandes refeições. O arroz e o feijão eram consumidos, diariamente, por $98,67 \%$, as carnes por $90,33 \%$ e os farináceos por $81,50 \%$. Os laticínios compunham a alimentação diária de $63,33 \%$ dos trabalhadores; $55,17 \%$ consumiam verduras e/ou legumes diariamente e $32,67 \%$, frutas. Em contrapartida, $53,00 \%$ mencionaram consumo diário de doces e refrigerantes e $38,67 \%$ de frituras e salgadinhos.

1 Artigo elaborado a partir da tese de M.A.T. MEDEIROS, intitulada "Riscos alimentares e nutricionais para acidentes do trabalho em Piracicaba, SP, Brasil". Universidade Estadual de Campinas; 2007. Apoio: Fundação de Amparo à Pesquisa do Estado de São Paulo (Fapesp, processo no 00/13719-3).

2 Pontifícia Universidade Católica de Campinas, Centro de Ciências da Vida, Faculdade de Nutrição. Campus II, Prédio Administrativo, Av. John Boyd Dunlop, s/n., Jardim Ipaussurama, 13060-904, Campinas, SP, Brasil. Correspondência para/ Correspondence to: M.A.T. MEDEIROS. E-mail: <angelicamedeiros@puc-campinas.edu.br>.

3 Universidade Estadual de Campinas, Faculdade de Ciências Médicas, Departamento de Medicina Preventiva e Social. Campinas, SP, Brasil.

${ }^{4}$ Universidade de São Paulo, Faculdade de Medicina de Ribeirão Preto, Departamento de Clínica Médica. Ribeirão Preto, SP, Brasil. 
$590 \mid$ M.A.T. MEDEIROS et al.

\section{Conclusão}

A alta prevalência de excesso de peso e os aspectos poucos saudáveis das práticas alimentares corroboram a tendência atual de aumento dessa doença, portanto, uma maior atenção a essas questões deve ser dada no tocante à vigilância à saúde dos trabalhadores.

Termos de indexação: acidentes de trabalho; estado nutricional; estudos transversais; inquéritos nutricionais; programas e políticas de nutrição e alimentação; saúde do trabalhador.

\section{A B S T R A C T}

\section{Objective}

To identify the nutritional status and dietary practices of injured workers of Piracicaba, São Paulo, Brazil.

\section{Methods}

Cross-sectional study with 600 injured workers seen at one of the 8 specialized centers of the city, between May and October 2004. The socioeconomic and occupational status, dietary practices and nutritional status (weight, height, waist circumference) were characterized, recording the means and standard deviation.

\section{Results}

The injured workers were mostly male (87.33\%) factory workers (55.17\%) with a mean age of 33 years. Most were formally employed (84.17\%) in a fixed day shift (91.00\%) and 55.33\% had a fixed job. Nearly half of them were overweight (28.26\%) or obese (17.89\%) and excess weight was more common among those whose work required little physical activity (54.90\%). Almost 1/3 of the workers had increased waist circumference, indicating cardiovascular risk. Most of the workers (85.33\%) had access to the worker's food program. Most of them had two large meals daily, lunch (95.67\%) and dinner (94.83\%). Some (24.16\%) did not have breakfast and some (37.50\%) had snacks in between meals. Rice and beans were consumed daily by $98.67 \%$ of the workers, meats by $90.33 \%$, starchy foods by $81.50 \%$, dairy by $63.33 \%$, vegetables by $55.17 \%$ and fruits by $32.67 \%$. On the other hand, $53.00 \%$ reported consuming sweets and sodas daily and $38.67 \%$ reported eating fried and salty snacks daily.

\section{Conclusion}

The high prevalence of excess weight and the not very healthy aspects of their dietary habits corroborate to the current trend of increasing obesity rates, therefore more attention needs to be given to issues regarding health surveillance of workers.

Indexing terms: accidents, occupational; nutritional status; cross-sectional studies; nutrition surveys; nutrition programmes and policies; occupational health.

\section{N T R O D U ÇÃ O}

Os acidentes do trabalho têm sido objeto de preocupação de pesquisadores e técnicos do campo da saúde coletiva no Brasil, como um problema de dimensões epidemiológicas. A precariedade do sistema de informações e a subnotificação, somadas às recentes mudanças no mundo do trabalho, como a desregulamentação e a crescente informalização do emprego, são alguns dos aspectos que evidenciam as dificuldades no tratamento dessa temática ${ }^{1,2}$.

A investigação das causas de acidentes do trabalho é matéria igualmente complexa, por se inserir na arena dos conflitos entre capital e trabalho, e envolver riscos de diversas naturezas relacionados, não apenas ao ambiente de trabaIho, bem como ao meio ambiente mais geral e aos conflitos sociais.

Um dos aspectos que podem interferir na ocorrência de acidentes diz respeito à alimentação do trabalhador que, para o exercício de suas funções, requer a satisfação de suas necessidades nutricionais. A influência do trabalho no estado nutricional e nas práticas alimentares tem sido investigada sob diferentes perspectivas.

Na literatura registram-se abordagens acerca dos efeitos do trabalho em turnos sobre a 
ingestão nutricional, como o estudo de Lennernas et al. ${ }^{3}$ que, examinando a influência do trabalho rotativo em três turnos sobre a distribuição cicardiana do consumo alimentar e os níveis de colesterol, de trabalhadores da indústria na Suécia, constataram que refeições do período noturno se relacionaram com níveis de colesterol sérico total mais elevados, apesar da menor ingestão identificada naqueles turnos. Na mesma direção, Assis et al. ${ }^{4}$, estudando a ingestão dietética de trabaIhadores da coleta de lixo de três turnos, em Santa Catarina, Brasil, verificaram consumo energético maior entre os trabalhadores noturnos, destacando que a carne foi o alimento que mais contribuiu para o aporte energético dos trabalhadores, nos três turnos. Por outro lado, Sudo \& Ohtsuka ${ }^{5}$, em pesquisa com trabalhadoras de uma fábrica de computadores no Japão, concluíram que o trabalho noturno condicionou uma menor ingestão de energia e de nutrientes em geral.

No Brasil, há vários estudos sobre o padrão de consumo alimentar em diferentes perfis de trabalhadores. Pesquisa com metalúrgicos do Rio de Janeiro, relacionando hábitos alimentares, estado nutricional e prática de atividade física, identificou prevalência elevada de sobrepeso nessa população ${ }^{6}$. Costa et al. ${ }^{7}$ encontraram associação positiva entre práticas alimentares, caracterizadas pelo consumo elevado de gorduras, e sobrepeso em trabalhadores do pólo petroquímico de Camaçari, BA.

Muito embora a discussão sobre questões alimentares e nutricionais relativas ao trabalho esteja presente na literatura, sua vinculação com acidentes do trabalho parece pouco estudada.

Segundo o princípio de que a vigilância à saúde dos trabalhadores deve contemplar a atenção aos aspectos nutricionais e alimentares, este artigo tem por objetivo caracterizar o estado nutricional e as práticas alimentares de trabalhadores acidentados atendidos em serviço de referência no município de Piracicaba, SP.

\section{MÉ T O D O S}

Este trabalho é um desdobramento da investigação "Diagnóstico e Controle de Acidentes do trabalho em Piracicaba" (DIATEP), desenvolvida entre março de 2002 e março de 2005, que se propôs a identificar, por meio de estudo epidemiológico de base domiciliar, a incidência de acidentes do trabalho no município nos setores formal e informal da economia, procurando, assim, estimar a subnotificação desses agravos ${ }^{8}$.

Os dados aqui analisados foram coletados no Centro de Ortopedia e Traumatologia de Piracicaba (COT), serviço que responde por $42 \%$ dos acidentes do trabalho que demandam assistência médica naquele município, constituindo-se em referência no atendimento de traumas ${ }^{9}$.

Durante todos os dias úteis, compreendidos entre maio e outubro de 2004, foram entrevistados todos os acidentados do trabalho que deram entrada no referido serviço. Duas nutricionistas, que receberam capacitação quanto à aplicação dos questionários e à padronização das medidas antropométricas, entrevistaram os trabalhadores acidentados, sob supervisão dos pesquisadores.

Como critérios de inclusão no estudo foram consideradas as seguintes condições: que durante o atendimento, e a eventual internação, os trabaIhadores acidentados se apresentassem clinicamente habilitados a responder a um questionário; e que concordassem em participar do estudo, mediante assinatura de termo de consentimento livre e esclarecido.

Ao darem entrada no COT, os trabalhadores acidentados, que concordaram em participar da pesquisa, tiveram a glicemia capilar aferida, com a intenção de identificar eventual estado de hipoglicemia, que poderia contribuir para a ocorrência do acidente. Na seqüência, os participantes responderam a um questionário indagando sobre condições ocupacional e socioeconômica, características do acidente sofrido e sobre as práticas alimentares. Informações referentes a esforço no trabalho, ganho ou perda de peso recentes e sua interferência no trabalho, bem como à presença de diabetes e hipertensão arterial, foram coletadas. Foi também verificado o estado nutricional dos entrevistados. 
A identificação do tipo de ocupação foi feita de acordo com a Classificação Brasileira de Ocupações $(C B O)^{10}$.

Em relação à situação trabalhista, os acidentados foram questionados quanto à inserção no mercado de trabalho, se formal ou informal; se possuíam local fixo de trabalho; sobre a jornada de trabalho diária em horas; os dias trabalhados por semana; o número de horas extras semanais; o tempo de início da ocupação atual e o tipo de turno de trabalho (diurno fixo, alternado, noturno fixo e misto). Foram ainda investigados os tipos de vínculo, se empregado típico, autônomo, doméstico, servidor público, bico, proprietário, estagiário ou temporário.

Para a verificação dos níveis de escolaridade foram definidos os seguintes critérios: escolaridade baixa, correspondendo a menos de 5 anos; escolaridade média, de 5 a 11 anos, e escolaridade alta, compreendendo mais de 11 anos de estudo formal. O esforço no trabalho foi classificado com base nos critérios da Food and Agricultural Organization (FAO) ${ }^{11}$.

Para a classificação do estado nutricional foram aferidas medidas de peso e altura, para cálculo do índice de massa corporal (IMC), e de circunferência de cintura, para estimativa de risco de doenças cardiovasculares, segundo critérios da Organização Mundial de Saúde ${ }^{12}$. A aferição do peso foi feita com o uso de balanças de $150 \mathrm{~kg}$, com precisão de $0,05 \mathrm{~kg}$. As pessoas foram pesadas descalças e vestindo roupas leves. A estatura foi verificada utilizando-se estadiômetros fixados em superfície plana (parede sem rodapés), os trabalhadores foram posicionados de forma ereta, tocando a parede em cinco pontos (calcanhares, panturrilhas, glúteos, ombros e cabeça), e com o olhar voltado para a linha do horizonte. A circunferência de cintura foi obtida mediante a utilização de fita métrica inelástica, posicionada no ponto médio entre a crista ilíaca e a última costela, e a leitura foi feita no momento de expiração ${ }^{12}$. Foram obtidas três medidas e calculada a média entre elas.
O estudo qualitativo das práticas alimentares dos trabalhadores acidentados buscou identificar a estrutura da alimentação (características das refeições ou das tomadas alimentares), investigando a regularidade e a freqüência de refeições e o consumo de alimentos por grupos ${ }^{13}$, por meio de um questionário fundamentado no que se considera como a dieta padrão dos brasileiros, na qual o arroz e o feijão são os alimentos básicos das grandes refeições, almoço e jantar; complementados por vegetais e/ou carnes $^{14}$. O instrumento elaborado (Anexo) continha questões abertas e fechadas, enfatizando tipos e número de refeições consumidas diariamente. A existência de usufruto de programa de alimentação (Programa de Alimentação do TrabaIhador - PAT) por parte dos trabalhadores foi também averiguada.

Foi realizada uma análise exploratória dos dados, para a qual se utilizaram modelos estatísticos freqüentistas, verificando medidas de posição central e de dispersão (médias e desvios-padrão - DP). O tratamento dos dados foi feito como o auxílio do programa estatístico The SAS System for Windows versão 8.0.

O trabalho foi aprovado pelo Comitê de Ética em Pesquisa da Faculdade de Medicina de Botucatu, da Universidade Estadual Paulista - UNESP/Botucatu (processo n 445/2004 - CEP).

\section{RES U LTA D O S}

Foram analisados 600 trabalhadores acidentados, a maior parte do sexo masculino (87,33\%), com 33 anos de idade, em média, variando entre 15 e 60 anos (DP=11 anos) e apresentando escolaridade média de 7,7 anos $(D P=3,19)$. Quanto à ocupação, verificou-se uma maior presença de trabalhadores na condição de operários (55,17\%). Observa-se, na Tabela 1, uma grande concentração de acidentes entre trabalhadores jovens, já que $42,51 \%$ deles ocorreram na faixa de 20 a 29 anos. 
Tabela 1. Caracterização social e ocupacional dos trabalhadores acidentados ( $n=600)$. Piracicaba, SP, 2005.

\begin{tabular}{|c|c|c|}
\hline Variável & Freqüência & Percentual \\
\hline \multicolumn{3}{|l|}{ Idade (anos) } \\
\hline 15 a 19 & 40 & 6,67 \\
\hline 20 a 29 & 255 & 42,51 \\
\hline 30 a 39 & 149 & 24,83 \\
\hline 40 a 49 & 112 & 18,67 \\
\hline 50 a 59 & 37 & 6,16 \\
\hline$>60$ & 7 & 1,16 \\
\hline \multicolumn{3}{|l|}{ Sexo } \\
\hline Masculino & 524 & 87,33 \\
\hline Feminino & 76 & 12,67 \\
\hline \multicolumn{3}{|l|}{ Escolaridade } \\
\hline Alta & 19 & 3,17 \\
\hline Média & 403 & 67,16 \\
\hline Baixa & 178 & 29,67 \\
\hline \multicolumn{3}{|c|}{ Tipo de trabalho } \\
\hline Fixo & 332 & 55,33 \\
\hline Não fixo & 268 & 44,67 \\
\hline \multicolumn{3}{|c|}{ Tipo de vínculo } \\
\hline Típico & 516 & 86,00 \\
\hline Autônomo & 57 & 9,50 \\
\hline $\mathrm{CLT}^{\star}$ & 18 & 3,00 \\
\hline Bico & 4 & 0,67 \\
\hline Doméstico & 3 & 0,50 \\
\hline Estagiário & 2 & 0,33 \\
\hline \multicolumn{3}{|c|}{ Inserção no mercado } \\
\hline Formal & 505 & 84,17 \\
\hline Informal & 95 & 15,83 \\
\hline \multicolumn{3}{|c|}{ Turno de trabalho } \\
\hline Diurno fixo & 544 & 90,68 \\
\hline Misto & 20 & 3,33 \\
\hline Não fixo & 36 & 5,99 \\
\hline \multicolumn{3}{|c|}{ Ocupações mais freqüentes** } \\
\hline Operário & 331 & 55,17 \\
\hline Setor serviços & 130 & 21,66 \\
\hline \multicolumn{3}{|c|}{ Nível de esforço no trabalho } \\
\hline Pouco & 122 & 20,33 \\
\hline Médio & 214 & 35,67 \\
\hline Muito & 264 & 44,00 \\
\hline
\end{tabular}

* Trabalho regido pela Consolidação das Leis Trabalhistas; **Há uma grande variedade nos demais tipos de ocupação, cuja freqüência compreende $23,17 \%$ (139) da amostra.

As causas imediatas dos acidentes se relacionaram, mais freqüentemente, a máquinas e equipamentos $(23,67 \%)$, a quedas de objetos $(23,67 \%)$ e a esforço excessivo ou peso $(13,00 \%)$.
As lesões decorrentes disso foram agrupadas em contusões $(46,67 \%)$, entorses $(14,83 \%)$, ferimentos corto-contusos $(10,33 \%)$ e fraturas $(9,00 \%)$, tendo como partes atingidas do corpo as mãos (36,50\%), os pés (18,50\%), os membros superiores $(14,67 \%)$ e inferiores $(14,00 \%)$ e a coluna $(9,33 \%)$.

Os entrevistados, em sua maioria, pertencem ao mercado formal $(84,17 \%)$, são trabalhadores típicos $(86,00 \%)$ e 55,33\% deles têm trabalho fixo, em turno, predominantemente, diurno fixo (91\%), perfazendo uma jornada diária média de 9 horas ( $D P=1,5$ horas) e cumprindo uma média de 4 horas extras de trabalho semanais $(\mathrm{DP}=7)$ (Tabela 1).

O exame da distribuição dos trabalhadores acidentados segundo a escolaridade mostrou uma maior freqüência naqueles com nível médio, correspondendo a 67,2\% da amostra. Os trabaIhadores com idades mais avançadas, em média $39,9$ anos ( $D P=11,5)$, apresentaram grau de instrução mais baixo. A média de idade daqueles com nível alto de escolaridade foi de 31,5 anos $(D P=9,4)$ e a dos com escolaridade média foi de 29,5 anos (DP=9,4).

No que se refere ao tempo de início da ocupação sob a qual os trabalhadores foram vitimados pelo acidente, detectou-se uma média de 4,06 anos ( $D P=8,3$ ). Observada relativamente à escolaridade, os que referiram menor grau exibiram uma média maior de anos do início da ocupação $(5,35$ anos, DP=7,96).

A duração média da jornada de trabalho foi de 9 horas $(D P=1,5)$, sendo menor nos acidentados com nível de escolaridade alta (7,7 horas, $D P=1)$. Para os de baixa e média escolaridade não houve variação na duração da jornada de trabalho $(9,2, D P=1,6$ e 9,1, $D P=1,4$, respectivamente). 0 mesmo se observou em relação à média de horas extras trabalhadas por semana (4,1 horas, DP=7,6 horas), também menor para aqueles com alta escolaridade $(2,9, \mathrm{DP}=7$ horas), comparativamente aos demais (baixa escolaridade, 4,4 horas, DP=8,8, e média escolaridade 4,1, DP=6,9 horas extras trabalhadas). 
594 | M.A.T. MEDEIROS et al.

Foram identificados sobrepeso em $28,26 \%$ e obesidade em $17,89 \%$ dos trabalhadores acidentados (Tabela 2). Risco (moderado e alto) de doenças cardiovasculares foi encontrado em $29,43 \%$ da população estudada.

Ao serem indagados sobre mudança de peso nos últimos 12 meses, 53,00\% $(n=318)$ dos

Tabela 2. Caracterização nutricional e de saúde dos trabalhadores acidentados ( $n=600)$. Piracicaba, SP, 2005.

\begin{tabular}{|c|c|c|}
\hline Variável & Freqüência & Percentual \\
\hline \multicolumn{3}{|l|}{$I M C^{*}$} \\
\hline Baixo Peso & 23 & 3,85 \\
\hline Eutrófico & 299 & 50,00 \\
\hline Sobrepeso & 169 & 28,26 \\
\hline Obesidade I & 81 & 13,54 \\
\hline Obesidade II & 26 & 4,35 \\
\hline \multicolumn{3}{|l|}{ Risco cardiovascular* } \\
\hline Baixo & 422 & 70,57 \\
\hline Moderado & 98 & 16,39 \\
\hline Alto & 78 & 13,04 \\
\hline \multicolumn{3}{|l|}{ Mudança de peso } \\
\hline Sim & 318 & 53,00 \\
\hline Não & 282 & 47,00 \\
\hline \multicolumn{3}{|c|}{ Interferência da mudança de peso no trabalho } \\
\hline Positiva & 279 & 46,50 \\
\hline Negativa & 28 & 4,67 \\
\hline Não sabe & 293 & 48,83 \\
\hline \multicolumn{3}{|l|}{ Benefício alimentação } \\
\hline Sim & 512 & 85,33 \\
\hline Não & 88 & 14,67 \\
\hline \multicolumn{3}{|l|}{ Tipo de beneficio $(n=512)$} \\
\hline Serviço próprio & 121 & 23,63 \\
\hline Terceirizado & 69 & 13,48 \\
\hline Vale-refeição/alimentaç̧ão & 110 & 21,48 \\
\hline Cesta básica & 191 & 37,30 \\
\hline Outros & 8 & 1,57 \\
\hline Sem informação & 13 & 2,54 \\
\hline \multicolumn{3}{|l|}{ Diabetes } \\
\hline Sim & 17 & 2,83 \\
\hline Não & 484 & 80,67 \\
\hline Não sabe & 99 & 16,50 \\
\hline \multicolumn{3}{|l|}{ Hipertensão } \\
\hline Sim & 59 & 9,83 \\
\hline Não & 509 & 84,84 \\
\hline Não sabe & 32 & 5,33 \\
\hline
\end{tabular}

* Excluídos dois casos por inconsistência de dados. IMC: índice de massa corporal. entrevistados relataram ganho ou perda de peso nesse período, conforme mostra a Tabela 2 . Desses, 189 (59,43\%) trabalhadores afirmaram ganho de peso, e o maior percentual ocorreu entre aqueles com sobrepeso, que ganharam, em média, 7,64kg ( $D P=17,38)$. Entretanto, chama a atenção o fato de os eutróficos também terem ganhado peso no período de um ano e, ainda, a média alta de ganho nos trabalhadores com obesidade de graus I e II (Tabela 3).

De acordo com a Tabela 3, os valores médios de glicemia capilar se situaram na faixa de normalidade, embora se possa constatar um gradiente consistentemente crescente ao transitar da condição de eutrofia para a de obesidade II.

O IMC foi considerado em relação ao nível de esforço despendido no trabalho, tendo-se observado que o sobrepeso ou a obesidade atingiram $54,92 \%$ dos que faziam pouco esforço, contra $42,06 \%$ dos que referiram atividades de esforço médio e 45,42\% dos que despendiam muito esforço. Essas diferenças, contudo, não se mostraram estatisticamente significantes (Tabela 4).

Da pesquisa sobre o benefício alimentação (PAT) constatou-se que a maioria dos entrevistados $(85,33 \%)$ referiu receber algum auxílio. 0 percentual de recebimento desse benefício, analisado segundo nível de escolaridade, não diferiu entre trabalhadores com escolaridade alta (73,77\%) e média $(72,04 \%)$, mas foi menor nos de baixa escolaridade $(61,24 \%)$.

Tabela 3. Média e desvio-padrão de ganho de peso $(n=189)$ e de glicemia capilar de trabalhadores acidentados $(n=600)$, segundo o estado nutricional. Piracicaba, SP, 2005.

\begin{tabular}{lcccccc}
\hline \multirow{2}{*}{ Estado nutricional } & \multicolumn{2}{c}{ Ganho de peso } & & \multicolumn{2}{c}{ Glicemia $(\mathrm{mg} / \mathrm{dL})$} \\
\cline { 2 - 3 } \cline { 6 - 7 } & $\mathrm{M}$ & DP & & M & DP \\
\hline Baixo Peso & 1,50 & 0,07 & & 95,48 & 17,12 \\
Eutrófico & 4,12 & 2,94 & & 103,75 & 25,27 \\
Sobrepeso & 7,64 & 17,38 & & 107,59 & 27,97 \\
Obesidade I & 6,30 & 2,33 & & 115,26 & 43,64 \\
Obesidade II & 5,00 & 4,72 & & 125,85 & 49,45 \\
\hline
\end{tabular}

M: média; DP: desvio-padrão. 
Tabela 4. Estado nutricional de trabalhadores acidentados $(n=598)$, segundo o nível de esforço no trabalho. Piracicaba, SP, 2005.

\begin{tabular}{lccccccccc}
\hline \multirow{2}{*}{$\begin{array}{l}\text { Estado } \\
\text { nutricional }\end{array}$} & \multicolumn{2}{c}{ Pouco } & & \multicolumn{2}{c}{ Médio } & & \multicolumn{2}{c}{ Muito } \\
\cline { 2 - 3 } & $\mathrm{n}$ & $\%$ & & $\mathrm{n}$ & $\%$ & & $\mathrm{n}$ & $\%$ \\
\hline Baixo Peso & 7 & 5,74 & & 6 & 2,80 & & 10 & 3,82 \\
Eutrófico & 48 & 39,34 & & 118 & 55,14 & & 133 & 50,76 \\
Sobrepeso & 40 & 32,79 & & 55 & 25,70 & & 74 & 28,24 \\
Obesidade I & 22 & 18,03 & & 23 & 10,75 & & 36 & 13,74 \\
Obesidade II & 5 & 4,10 & & 12 & 5,61 & & 9 & 3,44 \\
\hline Total & 122 & 100,00 & & 214 & 100,00 & & 262 & 100,00 \\
\hline
\end{tabular}

$\chi^{2}$ (teste qui-quadrado) $=11,41 ; 8 \mathrm{gl}$ (graus de liberdade); $p=0,18$ (nível de significância - $\alpha=0,05$ )

O consumo de bebidas alcoólicas foi referido por pouco mais da metade da população entrevistada $(58,17 \%)$, sendo que a cerveja foi a bebida com maior freqüência de relatos $(92,26 \%$, considerando $n=349$ ). A média de consumo foi de 1,77 doses $(D P=2,69)$ e o número de vezes por semana apresentou média de 1,17 ( $\mathrm{DP}=1,52)$. O hábito de fumar foi mencionado por $32,17 \%$ (193) dos acidentados, perfazendo 7,73 cigarros diários, em média ( $D P=11,31$ ). Declarados como ex-fumantes se encontraram 13,17\% (79) da amostra.

Os trabalhadores foram, ainda, indagados se eram portadores de doenças crônicas, como diabetes e hipertensão arterial. Somente 17 $(2,83 \%)$ responderam ter diagnóstico clínico de diabetes, distribuídos, de acordo com o estado nutricional, como segue: $7(41,8 \%)$ trabalha-dores com sobrepeso, 6 (35,29\%) com obesidade I, 02 $(11,76 \%)$ com obesidade II e 2 eutróficos $(11,76 \%)$.
Já a hipertensão arterial foi referida por 59 $(9,83 \%)$ entrevistados, acometendo $25(42,37 \%)$ acidentados com sobrepeso, 14 (23,73\%) com obesidade I, $10(16,95 \%)$ com obesidade II e 10 $(16,95)$ eutróficos.

No que tange às práticas alimentares, a maioria dos trabalhadores afirmou realizar as duas grandes refeições, almoço $(95,67 \%)$ e jantar (94,83\%), porém $24,16 \%$ deles disseram não tomar café da manhã diariamente. Boa parte dos sujeitos almoçava no próprio local de trabalho, seja levando comida de casa $(29,67 \%)$, seja porque ali se fornecia refeição (34,33\%). Apenas $4 \%$ referiram comer lanche no horário do almoço, em substituição a uma refeição típica. O jantar, por sua vez, era consumido, geralmente, em casa (89,17\%), já que são trabalhadores cujo turno é, na maior parte, diurno, conforme o mencionado. Nesse caso, observou-se, também, o predomínio de refeição típica (85\%) no lugar de lanches.

O consumo de alimentos entre as principais refeições (café da manhã, almoço e jantar) foi mencionado por somente $37,5 \%$ dos sujeitos.

Constatou-se um consumo diário de verduras ou legumes por $55,17 \%$ dos trabalhadores, e de frutas por $32,67 \%$. Já o hábito de ingerir diariamente arroz e feijão, combinação típica da dieta do brasileiro, foi referido por $98,67 \%$, e o de alimentos classificados como pães e farináceos, por $81,50 \%$. O leite e seus derivados também eram consumidos diariamente por mais da metade dos trabalhadores $(63,33 \%)$ e as carnes por $90,33 \%$. Por outro lado, 53\% mencionaram prática de consumo diário de doces e refrigerantes e $38,67 \%$ de frituras e salgadinhos (Tabela 5).

Tabela 5. Freqüência alimentar de trabalhadores acidentados $(n=600)$. Piracicaba, SP, 2005

\begin{tabular}{|c|c|c|c|c|c|c|}
\hline \multirow{2}{*}{ Alimento } & \multicolumn{2}{|c|}{ Diariamente } & \multicolumn{2}{|c|}{ Às Vezes } & \multicolumn{2}{|c|}{ Nunca } \\
\hline & $n$ & $\%$ & $n$ & $\%$ & $\mathrm{n}$ & $\%$ \\
\hline Verduras e/ou legumes & 331 & 55,17 & 240 & 40,00 & 29 & 4,83 \\
\hline Frutas & 196 & 32,67 & 345 & 57,50 & 59 & 9,83 \\
\hline Arroz e feijão & 592 & 98,67 & 6 & 1,00 & 2 & 0,33 \\
\hline Leite e derivados & 380 & 63,33 & 174 & 29,00 & 46 & 7,67 \\
\hline Pães e farináceos & 489 & 81,50 & 105 & 17,50 & 6 & 1,00 \\
\hline Carnes & 542 & 90,33 & 57 & 9,50 & 1 & 0,17 \\
\hline Frituras e salgadinhos & 232 & 38,67 & 341 & 56,83 & 27 & 4,50 \\
\hline Doces e refrigerantes & 318 & 53,00 & 262 & 43,67 & 20 & 3,33 \\
\hline
\end{tabular}




\section{DISCUSSÃO}

A idéia central deste trabalho foi descrever o perfil social, ocupacional e nutricional de trabalhadores acidentados de Piracicaba, sendo esta uma etapa preliminar relevante para o aprofundamento do processo analítico em estudos epidemiológicos.

Foi encontrada uma maior proporção de incidência de acidentes em adultos jovens do sexo masculino, o que vai ao encontro do perfil de acidentados em Piracicaba, verificado em estudos anteriores ${ }^{8,9}$, coincidindo, ainda, com os dados de investigações em outros municípios brasileiros ${ }^{15}$, o que sugere que esse tipo de agravo ocorre, provavelmente, em ocupações predominantemente masculinas.

A existência de 59,72\% de operários entre os acidentados parece indicar maior risco de sofrer acidentes no setor industrial. Registros recentes sobre a distribuição de acidentes do trabalho em Piracicaba, por ramo de atividade, com base nas estatísticas oficiais (Comunicação de Acidentes de Trabalho - CAT), contabilizaram $52,10 \%$ de ocorrências no setor da indústria, apesar da alta incidência também identificada no setor de serviços $(47,00 \%)^{9}$. O achado do atual estudo chama a atenção, frente às mudanças no mundo do trabalho, com o crescimento vertiginoso do setor de serviços e a retração do setor industrial no País. Ainda que estejam em discussão resultados de um estudo epidemiológico de base hospitalar, a expressiva proporção de acidentes do trabalho localizada no setor secundário da economia poderia falar em favor da importância econômica do município de Piracicaba. Todavia, estudos mostram que, malgrado o encolhimento industrial, esse setor ainda produz índices mais elevados de acidentes do trabalho ${ }^{16}$, possivelmente, por concentrar maiores riscos.

Embora os trabalhadores, em sua maioria, pertençam ao mercado formal $(84,17 \%)$ e possuam trabalho típico (86,00\%), somente $55,33 \%$ disseram ter trabalho fixo. Ou seja, a provável mobilização dos mesmos é mais um dado que reflete o cenário atual das condições de trabalho. A reestruturação produtiva, iniciada na década de 80 e acentuada nos anos 90, além de levar a um deslocamento da capacidade de absorção de mão-de-obra do setor secundário da economia para o terciário, e expandir as ocupações no segmento não-organizado do mercado de trabalho, estabeleceu novas formas de contratação, ampliando o trabalho temporário ${ }^{17}$.

Outra questão que pode ser pensada a partir deste resultado, de $55 \%$ de acidentados no setor formal, diz respeito à subnotificação dos agravos com trabalhadores informais, que chegam aos serviços sem o registro da CAT. Nesse sentido, a proposição de um sistema de vigilância, cujo ponto de partida foi implantar o Relatório de Atendimento ao Acidentado do Trabalho (RAAT), como produto da pesquisa DIATEP, anteriormente citada, faculta o registro de ocorrências dos setores formal e informal da economia. O RAAT vem cumprir, portanto, papel fundamental na superação da subnotificação, uma vez que foi implantado em todos os oito serviços de referência de atendimento de acidentados do trabalho de Piracicaba, formados por cinco pronto-socorros municipais e três hospitais privados ${ }^{8}$.

Em que pese a baixa freqüência de diabetes e hipertensão arterial referida pela população alvo, certamente, expondo os limites do método de coleta dessas informações, não se pode esquecer que as mesmas compõem o quadro de complicações metabólicas favorecidas pelo excesso de peso. Recentemente, em investigação com metalúrgicos de São Paulo identificou-se uma prevalência de $24,7 \%$ de hipertensão e de $11,5 \%$ de diabetes. O IMC, a hipercolesterolemia e a hipertrigliceridemia apresentaram associação positiva com essas enfermidades ${ }^{18}$.

Em relação à política de alimentação para o trabalhador, $85,33 \%$ dos entrevistados eram beneficiados, conforme o esperado, uma vez que a grande maioria pertencia ao mercado formal, e a cobertura desse benefício se circunscreve a esse setor. Verificou-se, também, que o acesso ao PAT para os trabalhadores com menor escolaridade foi bem inferior, relativamente àqueles com maiores níveis, o que coincide com outros estudos ${ }^{19,20}$. 
Quanto ao tipo de benefício alimentação recebido, mais da metade dos trabalhadores $(58,78 \%)$ deste estudo tem acesso às modalidades vale-refeição/alimentação e cesta de alimentos, o que se aproxima da proporção nacional. A cobertura do PAT no País, é de 9.329.234 trabaIhadores, dos quais $12,25 \%$ são beneficiados por serviços de alimentação próprios do local de trabalho; $18,56 \%$ recebem alimentação de serviços terceirizados e 4,20\% recebem refeições transportadas (marmita). A proporção de trabalhadores beneficiados por cesta de alimentos é de $17,08 \%$, sendo que $22,07 \%$ têm acesso a tíquete refeição e $25,83 \%$ a tíquete alimentação, totalizando, estas três últimas modalidades, 64,98\%²1 .

Observou-se uma expressiva prevalência de excesso de peso entre os trabalhadores acidentados (em torno de $46 \%$, somando sobrepeso e obesidade), confirmando a tendência atual de aumento desse agravo entre adultos. Resultado semelhante foi encontrado por Savio et al. ${ }^{20}$ que, em estudo transversal, com 1.044 usuários do PAT do Distrito Federal, encontraram excesso de peso em $43 \%$ deles.

Quando se localiza risco de doenças cardiovasculares, de moderado a alto, em 29,4\% da população alvo, tem-se mais um indício de uma situação merecedora de cuidado. A constatação de uma média alta de ganho de peso nos últimos 12 meses, entre os acidentados $(4,91)$, especialmente considerando que são adultos jovens, reitera a necessidade de vigilância.

Por outro lado, a relação entre esforço no trabalho e estado nutricional, ainda que, à primeira vista, sugira que quanto maior o esforço mais próximo da eutrofia se encontra o IMC, pode falar em favor de diferenças na composição corporal dos dois segmentos de trabalhadores, os que fazem um esforço médio e os com grande esforço no trabalho. Ou seja, mesmo apresentando um IMC menor que aqueles mais sedentários no trabalho, o valor do IMC dos que fazem maior esforço pode corresponder a uma massa muscular mais desenvolvida.

O crescimento da obesidade é um fenômeno contemporâneo, que afeta populações de países desenvolvidos ou não, e se relaciona com mudanças de diversas naturezas, envolvendo automação crescente do mundo da produção, novos padrões e comportamentos alimentares, influenciados pelo crescimento da indústria de alimentos, pelo ritmo urbano dos fast food e, até mesmo, pela patente violência urbana que invade o cotidiano, obrigando as pessoas a exercer cada vez menos atividades que consomem energia, como ir a pé ao trabalho ou se deslocar com os próprios pés.

No caso brasileiro, estudos relatam a tendência crescente da obesidade, em adultos e crianças, ao longo das últimas décadas ${ }^{22}$, que acompanha o aumento da prevalência de doenças crônicas, como hipertensão arterial e diabetes. Pesquisas realizadas com trabalhadores beneficiados pelo PAT ${ }^{18,23}$ corroboram essa constatação.

Estudos internacionais com trabalhadores têm, igualmente, encontrado elevados índices de obesidade, inseridos no cenário geral de doenças crônicas não transmissíveis 3,5,24.

Quanto às práticas alimentares dos trabalhadores acidentados, a preservação das duas grandes refeições, almoço e jantar, conforme os resultados, sinaliza para a manutenção do consumo de preparações que podem contribuir para uma alimentação saudável, exceto pelos acréscimos que estão incorporados. Cotejando estes resultados com o estudo qualitativo da freqüência alimentar, verifica-se que o predominante, nas grandes refeições, é a mistura arroz e feijão, acrescida da carne, compondo a refeição de mais de 90\% dos trabalhadores. Tal dado foi também descoberto em estudo que avaliou o almoço servido a usuários do PAT do Distrito Federal20, o que fala em favor da permanência de um padrão de dieta típico do brasileiro.

Os vegetais também estão presentes na alimentação dos entrevistados, todavia, para um pouco mais da metade. Por sua vez, as frutas fazem parte da rotina alimentar de apenas um terço dos trabalhadores, ou seja, parecem não ser alimentos tão valorizados e/ou incorporados à alimentação cotidiana. Tais achados se aproximam dos valores identificados em estudo recente, que 
verificou um consumo diário de vegetais de adultos brasileiros de $41 \%$ sendo um percentual ainda menor, 30\%, de consumo de frutas ${ }^{25}$.

Em contrapartida, os refrigerantes expandiram sua participação na mesa dos trabalhadores, pois 53\% o consomem diariamente, o que tem sido demonstrado em pesquisas de consumo alimentar $^{14,22}$. Refeições à base de frituras e salgadinhos também têm expressiva participação, considerando que seu consumo diário alcança quase $40 \%$ do grupo estudado. Pode-se supor que, mesmo mantendo algumas práticas alimentares tradicionais, consideradas saudáveis, o acréscimo energético advindo de itens como refrigerantes, salgadinhos e de preparações que utilizam muito óleo, como as frituras, justificaria a alta prevalência de sobrepeso ou obesidade entre os trabalhadores acidentados.

Levy-Costa et al. ${ }^{26}$, ao investigarem a distribuição domiciliar de alimentos no Brasil, a partir dos dados da Pesquisa de Orçamento Familiar (POF) de 2002-2003, verificaram que o grupo formado por legumes, verduras e frutas contribui com apenas 2,3\% do valor energético total da dieta dos brasileiros, enquanto que os alimentos essencialmente energéticos, incluindo as gorduras, os refrigerantes e o açúcar, representam 28,0\%.

A supressão do desjejum por $24,17 \%$ dos trabalhadores merece destaque, e como desdobramento deste trabalho, será possível investigar se a freqüência mais baixa de desjejum não se relacionaria com os acidentes do trabalho nesta população. Atenção deve ser dada, também, ao fato de $62,50 \%$ dos trabalhadores não se alimentarem entre as grandes refeições, já que o fracionamento da dieta constitui medida preventiva da obesidade.

O consumo de álcool pelos trabalhadores talvez tenha sido subestimado, dadas as circunstâncias em que foram coletados os dados desta pesquisa (no momento do atendimento médico ao acidentado), que podem ter inibido as respostas. Essa foi uma dificuldade também relatada em estudo com metalúrgicos do Rio de Janeiro ${ }^{6}$.

A reflexão sobre as práticas alimentares, à luz da referência de ganho de peso recente pelos sujeitos avaliados, configura um alerta para os formuladores de políticas de alimentação e nutrição voltadas aos trabalhadores. Indica que esta população está ganhando peso, tanto os eutróficos como os que já apresentam excesso. Em outras palavras, pode-se dizer que estes trabalhadores ou estão a caminho do excesso de peso ou mesmo agravando seu estado de sobrepeso ou obesidade, o que revela a necessidade de investimentos em medidas preventivas.

\section{CONCLUSÃ O}

Ainda que os trabalhadores acidentados preservem rotinas alimentares estruturadas, naquilo que se considera como o padrão dietético dos brasileiros, o que favoreceria uma alimentação balanceada, a interferência de práticas pouco saudáveis, com a ingestão de alimentos mais energéticos, é objeto de cuidado, sobretudo quando se constata uma alta prevalência de sobrepeso ou obesidade. Portanto, a vigilância à saúde dos trabalhadores deve contemplar a atenção aos aspectos nutricionais, sendo necessário investir em programas de educação alimentar preventivos da obesidade, e que também incentivem a prática do desjejum pelos trabalhadores, buscando implementar, ainda, outras tomadas alimentares no meio do dia sem, todavia, aumentar o consumo energético.

\section{COLABORADORES}

M.A.T. MEDEIROS participou da concepção do trabalho, da análise e da discussão dos resultados. $R$. CORDEIRO coordenou a pesquisa e participou da análise e da discussão dos resultados. L.T.O. ZANGILORANI participou da análise dos resultados e da discussão. R.W.D. GARCIA participou da concepção do trabalho e da discussão dos resultados.

\section{A GRADECIMENTOS}

Ao apoio financeiro concedido pela Fundação de Amparo à Pesquisa do Estado de São Paulo (Fapesp). Às nutricionistas Aline Maria Guizo, Kelly Cristina Coan e Rafaela Rossi Francisco, pelo apoio na coleta de dados. 


\section{REFER Ê N CIAS}

1. Cordeiro R, Sakate M, Clemente APG, Diniz CS, Donalisio MR. Incidência de acidentes do trabalho não fatais em localidade do sudeste do Brasil. Cad Saúde Pública. 2006; 22(2):387-93.

2. Wünsch Filho V. Reestruturação produtiva e acidentes do trabalho no Brasil. Estrutura e tendências. Cad Saúde Pública. 1999; 15(1):41-51.

3. Lennernas M, Akerstedt T, Hambraeus L. Nocturnal eating and serum cholesterol of three-shift workers. Scand J Work Environ Health. 1994; 20(6):401-6.

4. Assis MA, Nahas MV, Bellisle F, Kupek E. Meals, snacks and food choices in Brasilian shift workers with high energy expenditure. J Hum Nutr Diet. 2003; 16(4):283-9.

5. Sudo N, Ohtsuka R. Nutrient intake among shift workers in a computer factory in Japan. Int J Food Sci Nutr. 2001; 52(4):367-78.

6. Castro MBT, Anjos LA, Lourenço PM. Padrão dietético e estado nutricional de operários de uma empresa metalúrgica do Rio de Janeiro, Brasil. Cad Saúde Pública. 2004; 20(4):926-34.

7. Costa MC, Lessa I, Viana SV. Práticas alimentares e sobrepeso em trabalhadores de indústria petroquímica, Camaçari, Bahia. Rev Bras Saúde Ocupac. 2002; 103/104(27):117-26.

8. Cordeiro R, Vilela RAG, Medeiros MAT, Gonçalves CGO, Bragantini CA, Varolla AJ, et al. O sistema de vigilância de acidentes do trabalho de Piracicaba, São Paulo, Brasil. Cad Saúde Pública. 2005; 21(5):1574-83.

9. Medeiros MAT, Gonçalves CGO, Cordeiro R, Vilela RAG. Acidentes de trabalho em Piracicaba em 2002. Saúde em Rev. 2005; 7(15):7-13.

10. Instituto Brasileiro de Geografia e Estatística. Classificação de ocupações - censo demográfico de 2000 [acesso em 10 maio 2002]. Disponível em: http://www.ibge.gov.br/concla/ocupacao/cbo/ cbo.shtm

11. James WPT, Schofield EC. Necessidades humanas de energia: um manual para planejadores e nutricionistas. Rio de Janeiro: IBGE; 1994.

12. World Health Organization. Report of a WHO Consultation on Obesity. Obesity, preventing and management the global epidemic. Geneva; 1997.

13. Poulain JP. Contemporary diet in France: "de-structuration" or from comensalism to "vagabond feeding". Appetite. 2002; 39(2): 43-55.

14. Garcia RWD. Reflexos da globalização na cultura alimentar: considerações sobre as mudanças na alimentação urbana. Rev Nutr. 2003; 16(4): 483-92.

15. Lima RC, Victora CG, Dall'Ágnol M, Facchini LA, Fassa AC. Associação entre as características individuais e socioeconômicas e os acidentes do trabalho em Pelotas, Rio Grande do Sul, Brasil. Cad Saúde Pública. 1999; 15(3):569-80.

16. Santana V, Nobre L, Waldvogel BC. Acidentes de trabalho no Brasil entre 1994 e 2004: uma revisão. Ciênc Saúde Col. 2005; 10(4):841-55.

17. Pochmann M. O trabalho sob fogo cruzado: exclusão, desemprego e precarização no final do século. São Paulo: Contexto; 1999.

18. Martinez MC, Latorre MRDO. Fatores de risco para hipertensão arterial e diabete melito em trabalhadores de empresa metalúrgica e siderúrgica. Arq Bras Cardiol. 2006; 87:471-9.

19. Veloso IS, Santana VS. Impacto nutricional do Programa de Alimentação do Trabalhador no Brasil. Rev Panam Salud Publica. 2002; 11(1): 24-31.

20. Savio KEO, Costa THM, Miazaki E, Schmitz BAS. Avaliação do almoço servido a participantes do Programa de Alimentação do Trabalhador. Rev Saúde Pública. 2005; 39(2):148-55.

21. Brasil. Ministério do Trabalho e Emprego. Relatórios PAT [acesso em 2 mar 2007]. Disponível em: http://www.mte.gov.br/pat/relatorios

22. Instituto Brasileiro de Geografia e Estatística. Pesquisa de orçamentos familiares 2002-2003: análise da disponibilidade domiciliar de alimentos e do estado nutricional no Brasil. Rio de Janeiro; 2004.

23. Burlandy L, Anjos LA. Acesso a vale-refeição e estado nutricional de adultos beneficiários do programa de alimentação do trabalhador no nordeste e sudeste do Brasil. Cad Saúde Pública. 2001; 17(6):1457-64.

24. Koleva M. Nutrition, nutritional habits, obesity, and prevalence of chronic diseases in workers. Rev Environ Health. 1999; 14(1):21-9.

25. Jaime PC, Monteiro CA. Fruit and vegetable intake by Brazilian adults, 2003. Cad. Saúde Pública. 2005; 21(Sup):S19-S24.

26. Levy-Costa, RB, Sichieri R, Pontes NS, Monteiro CA. Disponibilidade domiciliar de alimentos no Brasil: distribuição e evolução (1974-2003). Rev Saúde Pública. 2005; 39(4):530-40.

Recebido em: 4/5/2007

Versão final reapresentada em: 16/10/2007 Aprovado em: 31/10/2007 
ANEXO

Questionário DIATEP - estudo caso-controle

Parte 1: dados gerais

Data da Entrevista __ _ _ _ / Entrevistador

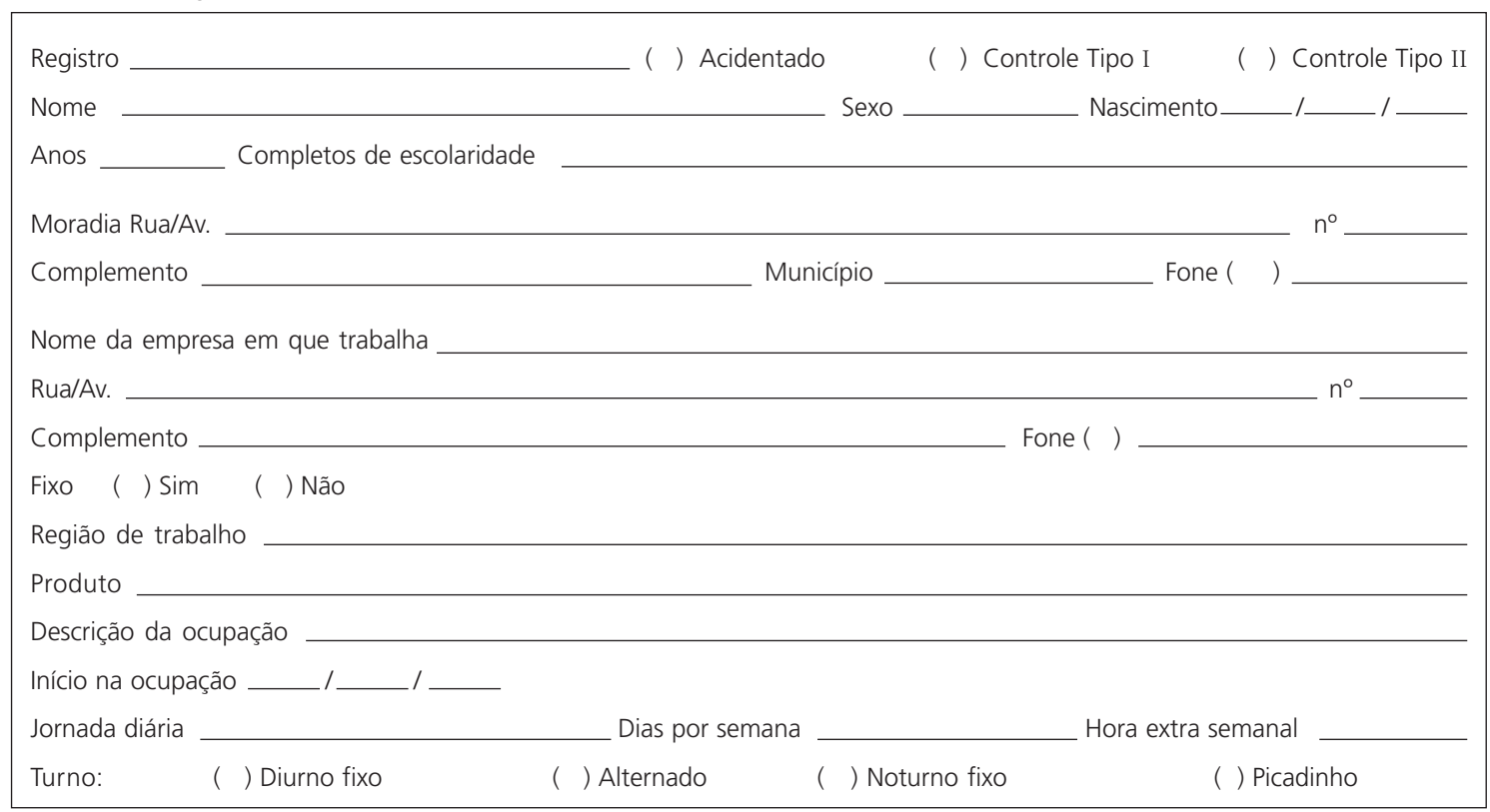

Tem contrato de trabalho ou carteira assinada?

( ) $\operatorname{sim}$

( ) Não

$\begin{array}{llll}\text { ( ) Empregado típico } & \text { ( ) Doméstico } & \text { ( ) Empregado típico } & (\text { ) Bico } \\ \text { ( ) Autônomo } & \text { ( ) Servidor CLF } & \text { ( ) Doméstico } & (\text { ) Proprietário } \\ \text { ( ) Temporário } & \text { ( ) Outros } & \text { ( ) Temporário } & (\text { ) Estagiário }\end{array}$

Só para casos

Data/Hora do acidente ___ _ _ _ _ ___ Data/Hora início da jornada ___ _ _ _ _ _ _ _ _

Local do acidente Rua/Av.

Complemento

Fone ( )

Descrição da atividade no acidente

Descrição sumária do acidente
CAT
( ) $\mathrm{Sim}$
( ) Não
( ) Não sabe
( ) Não se aplica

Causa imediata ( )

Outra

Lesão

Parte atingida

$N^{\circ}$ Total acidentes do trabalho anteriores

$N^{\circ}$ Acidentes do trabalho na ocupação atual

( ) Não lembra

Quando você se alimentou pela última vez antes do acidente?

O quê você comeu?

E após o acidente, você comeu alguma coisa? ( ) Não ( ) Sim Quando?

O quê você comeu? 
Só para controles

Quando você se alimentou pela última vez?
O quê você comeu?

Parte II: práticas alimentares

01. O quê você costuma comer no café da manhã?
( ) café preto ou chá
( ) vitamina/suco/leite
( ) come alguma coisa [pão/bolo/biscoito]

02. Você come alguma coisa no horário do almoço?

( ) sempre

( ) às vezes

( ) nunca

03. O que você almoça?
( ) um prato de comida
( ) outros O quê?

04. Onde você almoça?
( ) em casa
( ) no trabalho (fornece refeição)
( ) no trabalho (marmita)
( ) outro local. Onde?

05. Em quanto tempo almoça?

06. Você come alguma coisa no horário do jantar?

( ) sempre

( ) às vezes

( ) nunca

07. O quê você janta?
( ) um prato de comida
( ) outros O quê?

08. Onde você janta?
( ) em casa
( ) no trabalho (fornece refeição)
( ) no trabalho (marmita)

( ) outro local. Onde?

09. Em quanto tempo janta?

10. No período de trabalho come alguma coisa nos intervalos das principais refeições?
( ) sempre
( ) às vezes
( ) nunca

11. Em quanto tempo?
12. O que você costuma beber?
( ) destilados
( ) fermentados
( ) nada

13. Em que quantidade?

por dia,

vezes por semana

14. Quando você começou a beber?
15. Você fuma?
( ) $\operatorname{sim}$
( ) não, e nunca fumei

( ) não, mas já fumei no passado e parei há anos e meses

16. O que você fuma ou fumava?
( ) cigarro com filtro
( ) cigarro sem filtro
( ) cigarro de palha
( ) cachimbo
( ) charuto ou cigarrilha
( ) fumo de corda
( ) outros

17. Quanto você fuma ou fumava por dia? unidades

18. Quando você começou a fumar?

19. Quanto esforço você faz no seu trabalho?

( ) trabalha a maior parte do tempo sentado ou em pé parado?

( ) trabalha a maior parte do tempo se deslocando sem fazer grande esforço?

( ) trabalha a maior parte do tempo se deslocando e fazendo muito esforço? 
Só para trabalhadores formais

20. Você recebe algum benefício para alimentação? ( ) não
$\begin{array}{ll}\text { ( ) serviço próprio (empresa) } & (\text { ) terceirizado } \\ \text { ( ) vale refeição } & (\text { ) cesta básica } \\ \text { ( ) "quentinha" da empresa } & (\text { ) outros }\end{array}$

Freqüência alimentar

21.Você come verduras e/ou legumes?
( ) quase nunca
( ) de vez em quando
( ) sempre (1 ou mais vezes/dia)

22. Você come frutas?
( ) quase nunca
( ) de vez em quando
( ) sempre (1 ou mais vezes/dia)

23. Você come arroz e/ou feijão?
( ) quase nunca
( ) de vez em quando
( ) sempre (1 ou mais vezes/dia)]

24. Você come leite, queijos, iogurtes?
( ) quase nunca
( ) de vez em quando
( ) sempre (1 ou mais vezes/dia)

25. Você come pães, farinhas, macarrão, batata?
( ) quase nunca
( ) de vez em quando
( ) sempre (1 ou mais vezes/dia)

26. Você come carne, frango, peixe, porco?
( ) quase nunca
( ) de vez em quando
( ) sempre (1 ou mais vezes/dia)

27. Você come frituras/salgadinhos?
( ) quase nunca
( ) de vez em quando
( ) sempre (1 ou mais vezes/dia)

28. Você come doces e/ou refrigerantes?
( ) quase nunca
( ) de vez em quando
( ) sempre (1 ou mais vezes/dia)

Dados clínicos e antropométricos

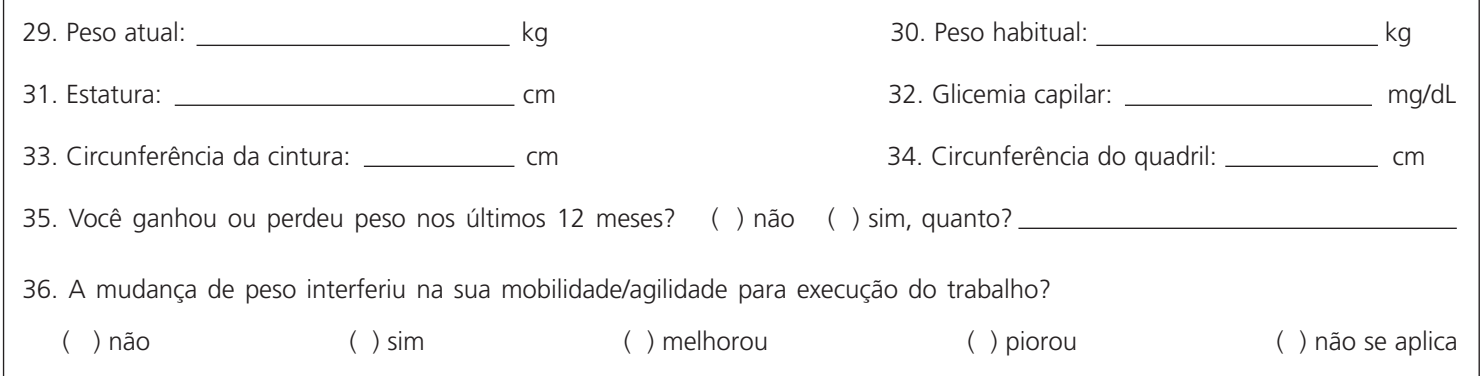

$\begin{array}{llll}\text { 37. É diabético: } & \text { ( ) } \operatorname{sim} & \text { ( ) não } & \text { ( ) não sabe } \\ \text { 38. Tem pressão alta: } & \text { ( ) } \operatorname{sim} & \text { ( ) não } & \text { ( ) não sabe }\end{array}$

